\title{
Public and Private in the Social Communications: Historical and Sociological Approach
}

\author{
Larisa Nikolaevna Fedotova \\ Faculty of Journalism, Lomonosov Moscow State University, Moscow, Russia \\ Email address: \\ fedotova117437@mai.ru \\ To cite this article: \\ Larisa Nikolaevna Fedotova. Public and Private in the Communication. International Journal of Literature and Arts. \\ Vol. 7, No. 5, 2019, pp. 112-117. doi: 10.11648/j.ijla.20190705.14
}

Received: June 24, 2019; Accepted: September 3, 2019; Published: September 20, 2019

\begin{abstract}
The article traces the evolution of the relationship between public and private during the development of human communication, starting from the earliest stages, when communication of a public nature was nothing more than a purposeful translation of general norms of behavior, taboos, beliefs, worldviews, attitudes toward power, helped to coordinate the efforts of the members of a clan, a tribe, in order to survive, to preserve some stability, to exist in time and space. Practically, such a model with some variations prevailed over a long period of human development. The new time has generated a new communication actor - a person who claimed to own a share of the private zone. In this sense, the practice of using social networks is interesting, with all their features within the stated theme: accessibility for supervising bodies and advertising are the defense of personal data, the possibility for communication in forums.
\end{abstract}

Keywords: Public / Private in Communications, Social Networks, Inclusion of Social Networks in Russia,

Trust in Information on Social Networks, Communication Features in Forums

\section{Introduction}

Recently, public interest in the problems of personal space in communications has intensified: scientific research is underway to identify the emotional, psychological, and content profile of personal content, and the topic of the lack of personal data on the Internet is being discussed. There have been frequent cases when the supervising authorities invade personal correspondence; the content of the reposts is monitored.

In this regard, it is interesting to trace the evolution of the ratio of public and private in the course of the development of human communication.

\section{Method}

In this article, analyzing the current ratio of public and private, interindividual, interpersonal communication in the communicative space, we turn to the history of human communication, starting from the very early period of the development of society, using a historical and sociological approach.

\section{Humanity at One Fire - The Public of Communication as the Need for Uniforming Opinions and Actions}

The habit of living together creates a common vocabulary. Stendhal (Marie-Henn Beyle). Walking around Rome

At first, the history of mankind was a development of a social organism, which, if it was visualized, could be represented as a kind of social pyramid, where the summit personifies Authority. In the tribal-communal system - we call so the tribal structure of the human body - it was the Leader, who was strong enough and, most importantly, had some knowledge that helped him coordinate the efforts of members of this genus, the tribe, to survive, to maintain some stability, to exist in time and space. Accordingly, social communication consisted in the transmission of general norms of behavior, taboos, beliefs, worldviews, attitudes towards the authorities, implementing obedience to Authority. And it was a public communication. Then the public completely absorbed the private or, even more, the latter simply did not exist (even sex was not private...), as 
there were no channels for private information sharing there was only a broadcast of a monologue, uniform, monolithic attitude to the world, coming from power institutions.

The essential characteristic of this communication was that all the members of the Tribe, subordinate to the leader, subject to the Leader, were some kind of uniform, homogeneous aggregate that existed publicly; the division of labor did not exist; rhythmic ritual dancing around the fire, coloring demonstrated uniformity. All this was the content of the human communication networks, or, figuratively speaking, the social umbilical cord that attached each individual to the genus and tribe. We note, without invading this issue - this is a separate case - in those times, far from us, there was no polyphony of voices in the spiritual life of mankind. For this to happen, a long historical period was needed...

\section{City Infrastructure for "Public Man" - Topography as a Continuation of Public Communication}

In this sense, a cross-section of this problem is interesting from the point of view of the history of human settlement. There are many cases accumulated by researchers that allow us to trace the evolution of the public in space throughout history. Especially a lot of evidence of this kind is accumulated by researchers on the example of Ancient Rome, whose urban infrastructure demonstrated a whole set of "public" buildings (theater, forum, circus, terms, basilicas, markets, etc.). Traditionally, they were located in the center of the urban settlement, in the place of public events of the city level. They (and here the researchers were unanimous) were the place of actualization of the "public man", which the historians call the Roman. These places were not the sum of the functional buildings that make up it, they were something bigger, it was the habitat of the city dweller.

We find interesting observations on this subject in Russian historical thought too. So, Klyuchevsky V. O. writes: "The external situation in which a person lives is no less expressive than his external appearance. His dress, the facade of the house that he builds for himself, the things with which he surrounds himself in his room, all this says about him and, above all, tells him to himself who he is and why he exists or wants to exist on the light. In ancient Russia it was different. The houses lived unpretentiously, somehow. People came home as if only to eat and rest, but they worked and thought and felt themselves somewhere on the side. The place of the best feelings and thoughts was the church. There the man carried his mind and his heart, and with them his wealth. Foreigners, entering the great ancient Russian city, were first of all amazed by the appearance of numerous stone churches". [1]
The idea of public space was embodied by communications in society. Even later processes in the communications of human civilization were described by some scientists in terms of space. Thus, the "global village", a well-known expression of G. McLuhan, refers to the role of electricity: "It instantly connects people all over the world, eliminates the line between day and night and turns the world into one "global village". [2]

The architecture of public space that came from antiquity gave rise to the publicity of the rituals of public life, about the beginning of which we have already spoken. But even later, the history of the development of mankind shows that many acts of public life took place publicly. Following the rituals of ancient man, we can mention folk culture, including the culture of medieval carnivals well described by $\mathrm{M}$. Bakhtin, and many ways of executing virtually all world religions, starting from the pagan base... Famous researcher of pre-feudal Europe A. Gurevich, describing norms of the implementation of the law among the ancient Scandinavians, writes: "It is possible to point out one feature common to all these ritual procedures - their public nature... Legal acts are carried out in public places, when people meet and with the participation of members of the assembly, a group of witnesses.... In an unwritten society, which was barbaric society, the ceremony performed the function that the document performs in a more civilized society (I singled out LF)". [3]

Further, the production of information became the function of individual social structures (religion, art, philosophy, science, developing production, jurisprudence, ethics), information became diverse, multi-valued, selfsufficient, sometimes contradicting the one that emanated from the center, from power structures. But for us it is now important that each of these social institutions has acquired its own audience, its own public. As part of our theme, it is important to emphasize that the initial stratification of society was associated with this (we omit the importance of economic stratification on the basis of the relationship to property).

In the literature, we find a scattering of evidence that group stratification and professional associations is supported by communications within these groups with tasks somewhat loosening the monologue of the center. Here the polyphonism of world representations of the new time which slowly but surely emerging. But for now they are looped into these strata and function inside them. One quote on this subject is so elegant that I want to bring it completely. And this quote from Cervantes is brilliant: "The vigilant author strictly ensures that his characters reasoned sensibly and expressed their thoughts with exquisite and clear, in full accordance with the position they occupy in society" (highlighted by me LF)! [4]

That is, purely spatial communication was locked in these enclaves, without ceasing to be public... 


\section{Economic and Political Foundation for the Emergence of the Subject of Private Individual Communication}

How did the evolution inside this dichotomy public/private later?

First, the subject of the private should have appeared the individual, not as a biological individual, but as a separate social individual recognizing itself as an individuality (1). For the time being, the human person did not exist as an autonomous subject of behavior and opinion; he was enmeshed, permeated with the traditional norms of behavior. Knowledge, skills, experience, forms of behavior of an individual were knowledge, skills, experience of a clan, a tribe... It was an essential characteristic of such a set of people over a sufficiently long period of time.

Capitalism made this man free economically, as a participant in mass production. This system made a person politically free, he gave him the opportunity to participate in the selection of the socio-political scenario of the development of society; provided him with unprecedented opportunities for social mobility, etc. As a result of participation in elections, democracy led to the emergence of parliament, on the arena in which discussions about social development took place with the participation of new social actors - parties that generated various socio-political programs [2].

The press appeared as an institution producing information for members of society: information is diverse, objectively offering choices, because it was information about reality, which becomes more diverse, changeable, as people's reaction, their opinions, tastes, needs, interests, values about it are varied [3].

\section{Public in the New Time - New Roles of Mass and Personality in History and New Forms of Mass Communication}

In social discourse it is very often possible to meet the combination of the role of the individual in history, with the statement that it has increased precisely in the new time. And this is pure true. But now I would like to focus on the seemingly opposite: on the increased role of the masses in history. Boris Andreevich Grushin wrote a lot about this a fundamentally new phenomenon, mentioning his predecessors. Indeed, although we have in the history numerous examples of social movements with numerous participants and even find the word mass in their description, it is always an accent on a large number of participants. Essentially they were such, but they were movements, separate, sharply stratified segments of the population (the revolt of the slaves of Spartacus, peasant wars / riots, religious wars) with pronounced social interests.

When we speak of mass as a new historical subject, we emphasize the syncretic nature of this phenomenon - the main thing in it is uniformity of the social role in relation to the law, to the place in the electoral mechanism of power, to the possibilities of vertical and horizontal mobility, etc.

But it is especially necessary to note the role of mass communications in these processes. The ideology of the emerging system of mass communications was that it implemented the idea of combining public and private in its own way.

First, by going along with its development in parallel with the formation of its audience, as consisting of personalities, it nevertheless built relationships with them according to the principle of "everything, everything, everything" and already by this fact alone massaged the audience, which in its own way recreates the idea of publicity. One of the functions of the system of mass communications according to Boris Grushin, just operates with the possibility of a separate component of this audience - the unit - to join "urbi et orbi", which practically implements the idea of communication with everyone.

Secondly, the system of mass communications in the same way seeks to exploit the homogeneity of emotions, experiences, value models, which prevailed in most public events of the past. And this is largely possible for her - it is enough to point out that, according to all ratings in all countries, on television in the first place audience consumes movies and television series.

Interest in cinema is understandable, and it has been analyzed by a multitude of cultural studies. In contrast to the mosaic of the world, which is created by the mediaman, in the cinema the consumer turns to the genre, which, like all art, gives the illusion of a simplified world.

The very behavior of the masses, potentially consisting in attaching to the dominant points of view - in information programs, entertainment, movies and TV shows - also goes back to the historical forms of communication in the public space.

One cannot but touch upon the problem of simultaneous existence in time and in human space of masses of people. This problem is presented in the works of many researchers, but Gustave Le Bon and Jose Ortega y Gasset are, of course, crowned with this list. We will further need the characteristics of this phenomenon that Gustave Le Bon systematized in his work "The Psychology of the Crowd". The Crowd is the name of the human aggregate, which in this quality acquires certain characteristics arising from the very fact of existence in time and in space: these characteristics are not reduced to the sum of the traits of the constituent individuals; people are in a state of emotional arousal; individuals "infect" each other with their feelings, thoughts, and actions. Susceptibility to suggestion in a crowd leads to the fact that individuals seem to disappear, "fall asleep" a conscious person; here people with a higher psychological organization go down to a lower level.

We find the authors even more categorical conclusion - 
here the personality disappears; the feelings and thoughts of individuals are leveled, as if it were means "people averaging". As a reason you can find the main thing - a person is anonymous in the crowd. Instead, an individual acquires the consciousness of his own strength because of the large number of people gathered - a strong motivation, rising genetically to the beginning of human history.

Currently, the topic of virtual crowds is actively discussed by psychologists, and just by Internet users, which are referenced by the mentioned authors [5-7].

We also must mention those characteristics of the crowd that the authors discussed, whose nature is purely psychological, and therefore goes back to the characteristics of individual individuals in this set: impulsivity, suggestibility, contrast in the formation of value judgments, figurativeness and illogical thinking. We also point out the physiological features of proximity of individuals here (tactile characteristics, facial expressions, gestures, and expressive exclamations) highly appreciated by participants of such scenes - recall the crowds on Nikolskaya Street in Moscow during the world football championship (2018) and similar meetings of fans in other cities of Russia.

\section{Public / Private Symbiosis - Social Networks}

Today, a person who does not have accounts in social networks, first arouses suspicion, then interest arises, then pity, and in the end envy.

From anecdotes.

How has this opposition to the public-private so-called mediation of the information space affected? At one time, for example, the rapid development of telephone installation (including faxes) was considered by communication theorists as an extension of interpersonal communication capabilities. Of course, technologically it is in the development of social networks. Indeed, starting in the early $2000 \mathrm{~s}$, the process of connecting the masses to social networks changed the nature of the information consumption itself - here it is combined with the audience with the exchange of personal information in the closest circle of relatives and friends (1), the possibility of simultaneous production of information (2), finding a single platform in the Internet space of a variety of information services and services (3). Paraphrasing the characteristics of social networks from the point of view of our perspective to what extent they provide opportunities for the private information space - we must emphasize the fundamentally important possibilities.

First of all, it is an opportunity to exchange with your counterparties personal information inaccessible to those for whom it is not intended (a); receive information from those who produce it in the same space (b); express his point of view in a monologue, the text is not subject to any editing (c); and finally - a person feels himself in a space where the essential characteristics of his safety in society are in effect: in this case, informational (the rest did not agree to cumulatively white to black, dominated by ideas that generally correspond to common sense, the future is not given for the past, etc.) (d) This is like the attitude of the modern man - in society the laws of the jungle are forbidden, civilization is used to mark many things as crimes, etc., and if this prevails, it is only in the dystopias of modern writers who write about the disintegration of civilization.

What are the possibilities of social networks to realize these potencies?

Today in our country the exit of the audience in social networks is as follows. The Levada Center survey (March 2018) shows such answers to the question "Do you visit social networks on the Internet? If so, how often? "daily/almost daily - 36\%; never - 40\%. [8]

But it turned out over time that communication with their close ones, with the circle entering the immediate environment of the individual, is almost transparent for two powerful players in the information space - advertisers and government officials. Spam in the form of contextual advertising flooded users' personal mail. Suppose you can ignore it. But the very access to the keywords of our messages, according to which a package is formed for, as it were, personal sentences, leaves a weighty consideration how far can these technologies go....

It is known that the selection of messages for keywords from the current political dictionary. A second problem is connected with this.

Another position is related to the expectation of receiving information. And this is often not sharing information. The participation of the majority of users is reduced to its consumption - this time (as opposed to the classical model of functioning of mass communication) from the lips of professional bloggers. This is actually the basic law of communication: all sociological studies show that the appeal of the audience to information channels is motivated primarily by the desire of people to learn about the events that have just happened in the world, in the country, in their city. No wonder the news is the brightest calling card of journalism, the transfer of the functions of the latter begins with an informative; practically the novelty and efficiency of communications constitute a certain imperative of journalism as a professional activity. But in social networks, this model is slightly modified - the filtering of information through the channels of interpersonal communication in the same social networks is turned on.

So, users themselves differentiate their news channels. Levada center cites the following data [9]: 
Table 1. Answers to the question "Which of the following statements are suitable for you?" (In \% of respondents who use social networks; respondents were offered a card and they could choose more than one answer; ranked by column "by sample" descending).

\begin{tabular}{|c|c|c|c|c|}
\hline \multirow{2}{*}{ Statements } & \multirow{2}{*}{$\begin{array}{l}\text { In the total for } \\
\text { the sample }\end{array}$} & \multicolumn{3}{|c|}{ Different age groups among users of social networks } \\
\hline & & 18-29 & $30-49$ & 50 and older \\
\hline I receive news from friends and relatives in social networks & 38 & 39 & 38 & 37 \\
\hline I follow news agencies in social networks & 26 & 24 & 29 & 24 \\
\hline I follow the pages of famous journalists (TV, newspapers) in social networks & 14 & 16 & 13 & 14 \\
\hline I get news from people I don’t personally know & 14 & 14 & 16 & 8 \\
\hline I follow the pages of celebrities who discuss news on social networks & 11 & 15 & 10 & 10 \\
\hline None fit & 29 & 30 & 27 & 33 \\
\hline
\end{tabular}

In the traditional information channels the audience have settled down some models of news consumption: a selection mechanism has several positions - first of all, trust in the source; place on the band / on the air; topics related to this place; a heading that builds on tough professional requirements, which boil down to the fact that the heading should have brought the consumer to the fullest extent possible.

Unprincipled differ from this model of information consumption in social networks. The reaction to the source by the majority of consumers is connected with the person's fame, trust in her - is the fundamental basis for addressing her; further, momentary considerations of the extraordinary, sensational nature of the event itself take place...

But the corps of newsletters on the Internet is by no means exhausted by bloggers. In this space, there are news aggregators, which with the help of robots automatically collect news content from information sources and place it in the field of interpersonal communication - in the personal mail of the consumer. Moreover, lately a package of such spam-introduction contains as content claiming to be recognized as information; on the other hand, an advertisement is immediately placed. The tendency is that this news, in the case of high demand, which means the rating, which lies at the base of its selection for a robot presentation, can spin in this drum in a few days, sometimes weeks!

Another noticeable characteristic is the restriction for the consumer of the basis for selection. Here, the emphasis is only on the title (and in the classical channels, as we have said, this can be a long relationship practice, a place in the information flow, etc.). And the headline of such news is very transformed. Often it is not supported by the text itself; in fact, it often repeats the ridiculed formula - the news is when not the dog bites a person, but the person a dog; it works mainly with the figures that are always in the top spots of the news flow - thus realizing the technology of celebrities that is characteristic of advertising. In general, this technique allows us to recall the often repeated reproach to the address of advertising - the maximum aggressiveness of the impact.

But we must add here as a sign of the changed information situation - the appearing of the fake news industry, which are being introduced with their products to the blogosphere. If we take into account that these products are the content of corporate communications, then it remains to be recognized that today they substantially push back the product of journalism.
May be this is the reason why only 18 percent of the respondents from the ZIRCON research group trust the information in online publications ("Image of Journalist in the Mass Consciousness of Russians" project, commissioned by the Media Research Foundation and the development of journalism standards)?

In general, half of the survey participants agreed with the statement "I do not believe the majority of media reports," more than half of the respondents (58 percent) did not agree with the statement "I used to believe what they write in newspapers, say on TV and radio". In both cases, distrust clearly prevails over trust, the study says. [10]

But of course, the most interesting thing in the new practice of developing the information space of social networks is forums in which participants actually exchange information, record assessments, put forward versions in the case of extraordinary events.

Here, the private strives for publicity - it is the latter that is the desired result for individuals. Some bloggers are quoted by quite respectable information channels, invited to their pages / broadcast. It was not by chance that we gave a detailed analysis of the behavior of individuals in a crowd (see above) - here we are clearly dealing with a phenomenon that could be called a virtual crowd (now it is already a common thought, but it doesn't make it any less fair). The sharp demarcation of the estimated, lack of halftones, vocabulary on the verge of a foul (anonymity frees up), following evaluative dominants, which dislikes-likes system contributes not to a small degree. But the word croud is single-rooted with crowdsourcing and crowdfunding, which, of course, gives the word some respectability.

And if the bell tongue has swung as much as possible in this direction - in the direction of new communicative practices, towards the deepest immersion in the social network, will there not be a reversal? Will users not look for other forms of interaction, more tactile, with facial expressions, with smiles, with interjections - with what people came to Nikolskaya street for (figuratively speaking)?

After all, history tells us at least two such empirical facts: in the USA in 1930 only $40 \%$ of Americans had a radio at home; in 1940, on average, there were 1.4 radio receivers per household. [11] And at the same time, the maximum number of film visits per year in the entire history of cinema - a fact that all film experts say. And this is despite the fact that the country was experiencing the deepest economic crisis in the entire history of the country. Did they want to feel some community? Demonstrations that we exist? 
The second fact: 30-50 years of the twentieth century in the United States, when the expansion of radio was joined by the expansion of television (it became the most consumed source of information in the 50s) - they give such a figure card sales (!!!) - about 50 million annually decks, and in 1900 16.5 million decks were sold. Amateur playing cards has become one of the typical activities for family and friend groups, sometimes for the sake of feasts and games as end in themselves — people gathered from the desire for personal entertainment and pleasant communication with other people close to them.

\section{Conclusion}

So, the information, used in our analysis, is based on the historical approach to the study of society, which consists in the fact that behind an infinite mass of empirically random relationships and situations, there are constant, strong connections between different spheres of society. History helps look at society as a whole object. as a complex object with a system. The process is considered as natural.

It is fundamentally for us to turn to the sociological vision of what is happening, to consider social phenomena in the whole complex of its components; consideration of any social fact in a wider social context, in the whole variety of social ties: economic, political, moral, religious... The peculiarity of this way of seeing social reality is a look through the prism of human activity involved in this social process of forces.

With this in mind, the ratio of public and private in human communication during the development of society went through different stages, which we described in subsections the priority of the public communication in the first stages, due to the functional need to ensure the monolithic effort of the clan, tribe to maintain its stability, and the evolution of the process towards the value of private communication of a new historical subject - personality, and its new role in a new type of society.

It seems that with the development of social networks, private forms of communication threaten to completely absorb the public being of a person. Nevertheless, we see the reverse process too (the volunteer movement, sport as a spectacle for the masses, role-playing games, festivities, group forms of leisure, etc.): "a social person" requires more and more flexible forms of communication in a privatepublic dichotomy.

We will observe what the trends of this process will be characteristic in the near future.

\section{References}

[1] Klyuchevsky V. O. (1990) O vzglyade hudojnika na obstanovku i ubor izobrajaemogo im litza // Istoricheskie portrety. M.: Pravda, S. 29-39. [On the artist's view of the situation and the appearance of the person depicted by him // Historical portraits. M.: True, P. 29-39].

[2] Tz. po: Arkhangelskaya I. B. (2007) Marshal Gerbert Makluen. Ot isslefdovaniy literatury $\mathrm{k}$ teorii massmedia. M.: Izdatelstvo Moskovskogo Universiteta, S. 17. [Quoted from by: Arkhangelskaya I. B. Herbert Marshall McLuhan. From the study of literature to the theory of mass media. Moscow: Moscow University Press, P. 17].

[3] Gurevich A. (1999) Izbrannye trudy. Vol. 1. M.- Spb. M.: True, [Gurevich A. Selected Works. M.- SPb., vol. 1, P. 262].

[4] Servantes Saavedra Migel. (1988) Hitroumnyj idalgo Don Kihot Lamancheskiy: v 2-h knigah. Kniha 1. Alma-Ata: Mektep. C. 43. [Cervantes Saavedra Miguel. Cunning hidalgo Don Quixote de La Mancha: in 2 books. Book 1, Alma-aty: Mektep,. P. 43].

[5] Available from https://www.liveinternet.ru/users/natalichkai/post356861056/ [Accessed: 20/08/2019].

[6] Available from https://a-bugaev.livejournal.com/1149171.html [Accessed: 20/08/2019].

[7] Goryachev A. V., Kazakov U. N. Deystvie zakonov formirovaniya tolpy $\mathrm{v}$ prilojenii $\mathrm{k}$ virtualnomu prostranstvu seti internet [Goryachev A. V. Kazakov Yu. N. The application of the laws for forming a crowd in annex to the virtual space of the internet network] Available from https://cyberleninka.ru/article/n/deystvie-zakonovformirovaniya-tolpy-v-prilozhenii-k-virtualnomuprostranstvu-seti-internet [Accessed: 20/08/2019].

[8] Available from https://www.levada.ru/2018/04/18/informatsionnyeistochniki/?utm_source $=$ mailpress\&utm medium $=$ email link \&utm_content $=$ twentyten_singlecat_20006\&utm_campaign $=2$ 018-04-18T07:00:10+00:00. [Accessed: 20/08/2019].

[9] Available from https://www.levada.ru/2018/03/06/sotsialnyeseti/?utm_source $=$ mailpress\&utm_medium $=$ email_link\&utm content=twentyten_weekly_19536\&utm_campaign $=2018-03-$ 10T13:00:08+00:00 [Accessed: 20/08/2019].

[10] Available

from https://news.mail.ru/society/35123405/?frommail=1 [Accessed: 20/08/2019].

[11] Lowery S., De Fleur M. (eds). (1983) Milestones in Mass Communication Research. N.Y., L., P. 107. 